\title{
КЛАССИФИКАЦИЯ УСТОЙЧИВЫХ ЛОГИСТИЧЕСКИХ РЕШЕНИЙ: МНОГОКРИТЕРИАЛЬНЫЙ ПОДХОД
}

\author{
(C) 2019 Цзоу Тун \\ аспирант, кафедра логистики и управления цепями поставок \\ Санкт-Петербургский государственный экономический университет \\ 191023, Санкт-Петербург, ул. Садовая, д. 21 \\ E-mail: tszou.tun@yandex.ru
}

В настоящее время в научных кругах все чаще обсуждается концепция экологической (зеленой) логистики как фактора устойчивого развития в экономической, социальной и экологической сферах жизни общества. В рамках данной статьи автором сделана попытка проанализировать основные тренды логистики в концепции устойчивого развития, следование которым уменьшает отрицательные воздействия компании на экосистему, сокращает нагрузку на окружающую среду и уменьшает затраты по всей цепи поставок. Разработан классификатор устойчивых логистических решений по ряду параметров. Выявлены основные проблемы, с которыми сталкиваются компании при попытке перехода к концепции устойчивой логистики, и обозначены основные направления решения этих проблем.

Ключевые слова: устойчивое развитие, зеленая логистика, экологическая логистика, устойчивая логистика, устойчивые логистические решения.

Понятие «устойчивое развитие» получило широкое распространение в 80-е гг. 20 века, после выхода в свет доклада $\mathrm{OOH}$ «Наше общее будущее», в котором Организация Объединенных Наций обратила внимание на необходимость «удовлетворения реальных потребностей сегодняшнего времени, не подрывая способности удовлетворять собственные потребности будущих поколений» [3]. В 2001 году Европейский союз признал устойчивое развитие «фундаментальной и всеобъемлющей целью». Миссии всех передовых мировых компаний (Unilever, IBM, IKEA и многих других) содержат в себе цели устойчивого развития.

Можно выделить следующие предпосылки развития концепции устойчивого развития [8]:

- многочисленные экологические катастрофы, связанные с деятельностью производственных и транспортных предприятий (Бхопал (1984), Базель (1986), Чернобыль (1986), Мексиканский залив (2010), Фукусима (2011) и мн.др.);

- ограниченность природных ресурсов, исчерпание нефти, природного газа, угля, пресной воды, древесины, цветных металлов;

- глобальное потепление и «парниковый эффект»;

- снижение биологического разнообразия, загрязнение атмосферы и водной среды;

- социальное неравенство, возрастающая безработица;
- разрыв в социально-эконмическом развитии между группами «богатых» и «бедных» стран;

- демографическая проблема (демографический взрыв в развивающих странах, демографический кризис в развитых странах);

- проблема «глобальных» заболеваний (онкология, СПИД).

Исторически в термине «устойчивое развитие» выделяют 3 важнейших взаимосвязанных аспекта:

1. Экономический: сохранение или увеличение различных видов капитала (производственный, естественный, человеческий, социальный), обеспечивающих экономическое производство.

2. Экологический: сохранение экосистем и природных ресурсов для устойчивого экономического производства и межпоколенного равенства.

3. Социальный: обеспечение социального равенства, удовлетворение базовых потребностей в здоровье и образовании.

Таким образом, изначально понятие «устойчивое развитие» рассматривалось в глобальном значении в контексте пересечения предметных областей экономики, экологии и социологии. Затем в связи с проблемой ограниченности ресурсов устойчивость стали рассматривать в контексте отдельных структурных элемен- 
тов - предприятий и их подсистем, среди которых особую роль приобретают логистические процессы, которые связывают компанию с окружающей средой, другими фирмами, поставщиками, клиентами, регионами и обществом [6].

При управлении логистической деятельностью предприятия растет роль экологических факторов, что вызвало появление в научном и практическом обиходе таких терминов как «зеленые цепочки поставок», «зеленая логистика», «экологическая логистика». Термин «устойчивая логистика» также является широко употребляемым, однако на данный момент не является полноценным научным понятием. Автором дается следующее определение термину «устойчивая логистика»: это процесс планирования, реализации и координации движения различных видов потоков и ресурсов на всех этапах цепи поставок, основной целью которого является удовлетворение потребностей производителя и потребителя при минимизации негативного влияния на окружающую среду и общество, при достижение стабильного баланса между экологическими, экономическими и социальными задачами логистической системы.

Можно выделить следующие тренды логистики в концепции устойчивого развития, наиболее актуальные на сегодняшний день: [составлено автором при использовании [1], [3]]

1) снижение расстояния при перевозке грузов на всех стадиях цепи поставок, увеличение использования локальных ресурсов, переориентация на «местных» поставщиков;

2) выбор более экологичных видов транспорта (трубопроводный, внутренний водный, морской и железнодорожный), развитие мультимодальных перевозок;

3) кастомизации товаров по заданным паттернам, что дает возможность уменьшать запасы готовой продукции на складе;

4) развитие формата «магазин-склад», что позволяет повысить оборачиваемость, одновременно снизив расходы на сбыт и логистику за счет уменьшения потребности в презентационных площадях и логистическом персонале и снижения многих видов логистических рисков;

5) появление автоматизированных (беспилотных) логистических систем, что позволяет снизить трудоемкость процесса доставки, интегрировать эффективные алгоритмы доставки (основанные на нейронных сетях), повышая, таким образом, экологичность и энергоэффектив- ность процесса доставки и развивая комплексную логистическую среду;

6) развитие электронной торговли и цифровизация логистики, что позволяет управлять потреблением ресурсов и добиваться максимально эффективного их использования, прорабатывая вопросы надежности логистических процессов и устойчивости качества продукции, следования требованиям экологической маркировки, устранения негативных воздействий логистики на окружающую среду и общество.

Необходимо провести классификацию «устойчивых» логистических решений по ряду параметров:

1. В качестве первого классификационного критерия можно рассмотреть упомянутые выше три аспекта устойчивого развития (экологический, экономический, социальный): [Составлено автором при использовании [6], [7]].

Экологический аспект устойчивой логистики предполагает ликвидацию негативных воздействий на окружающую среду, возникающих в процессе транспортировки сырья, материалов, полуфабрикатов и готовой продукции. Основные решения в области ликвидации упомянутых негативных последствий лежат в области использования методов и технологий реверсивной логистики.

Экономический аспект устойчивой логистики предполагает минимизацию логистических затрат на протяжении всей цепочки поставок, а также повышение добавленной стоимости продукции для потребителей за счет использования «устойчивых» логистических технологий.

Социальный аспект устойчивой логистики изучает воздействие на общество, людей, регионы, культуру через логистические процессы фирмы и её взаимодействие с окружающей средой, а также применение принципов корпоративной социальной ответственности в логистической деятельности организации.

2. В качестве второго классификационного критерия можно рассмотреть уровень решаемых логистических задач, среди которых выделяют стратегические и оперативные.

К стратегическим задачам устойчивой логистики можно отнести следующие:

- интеграция и оптимизация первичной и вторичной логистических цепочек;

- оказание влияния на всех контрагентов (поставщиков, клиентов и т.д.) для достижения наибольшего эффекта в логистических процес- 
сах и создание устойчивых цепей поставок;

- уменьшение затрат на логистику при одновременном увеличении добавленной стоимости продукции в процессе интеграции устойчивых логистических решений;

- повышение гибкости в изменении сроков поставок, а также объёмов и свойств продукции;

- внедрение инновационных технологий с целью уменьшения экологические нагрузки на окружающую среду;

- развитие цепочек поставок с обратной связью.

K оперативным задачам устойчивой логистики можно, в качестве примера, отнести следующие:

a) сокращение количества транспортных средств, имеющихся на предприятии и не используемых по назначению;

б) сокращение времени ожидания поставки заказчиком;

в) реализация природо-, энерго- и материалосберегающих технологий на всех этапах цепи поставок

г) максимальное использование отходов производства, вторичная переработка упаковки или безопасная ее реализация.

3. В качестве третьего классификационного критерия можно рассмотреть применение устойчивых решений в различных логистических подсистемах: [составлено автором при использовании [5], [9]]:

- производственная логистика (политика «ноль дефектов», уменьшение товарно-материальных запасов, использование возобновляемых источников энергии);

- транспортная логистика (мультимодальные перевозки, 3PL-логистика, уменьшение доли автомобильного транспорта (как наименее экологичного) с пользу железнодорожного (как оказывающего наименьшее влияние на окружающую среду), консолидация грузовых партий в логистических каналах, снижение расстояния при перевозке грузов за счет увеличения использования локальных ресурсов);

- складская логистика (использование возвратной тары, экологические проекты по строительству складов с использованием энергосберегающих технологий и экологически чистых строительных материалов, уменьшение запасов для сокращения потребности в складских площадях);
- реверсивная логистика (управление отходами, уменьшение воздействия упаковочных материалов на окружающую среду).

4. В качестве четвертого классификационного критерия автором предлагается рассматривать различные логистические решения согласно направлениям воздействия на окружающую среду [2]: экономия топлива, экономия воды, экономия невозобновляемых природных ресурсов уменьшение загрязнения воздуха, воды и почвы.

5. Безусловно, логистические технологии транспортировки различаются по степени устойчивости в различных секторах экономики. Например, при перевозке продукции химической промышленности (нефтепродукты, кислоты, удобрения, полимеры) следует выбирать такие более экологически безопасные виды транспорта как трубопроводы, внутренние водные пути, морские и железнодорожные [1].

В целом, несмотря на то что положительный эффект от перехода к концепции устойчивой логистики очевиден и крайне необходим, в практической деятельности предприятий этот переход вызывает определенные затруднения.

Во-первых, это связано с тем, что существующие на сегодняшний день инструменты устойчивой логистики носят разрозненный характер, из-за чего соответствующие мероприятия реализуются не достаточно системно, часто имеют противоречивый характер, из-за различий их вектора совокупная результативность снижения вредного воздействия логистики на окружающую среду получается низкая.

Во-вторых, руководство компаний не видит прямой экономической выгоды от реализации мероприятий устойчивой логистики, однако затраты на них весьма явные и обширные.

Одним из путей решения данной проблемы автору видится разработка детализированной системы показателей устойчивости логистической подсистемы предприятия по таким составляющим как энергопотребление, потребление водных ресурсов, материалоемкость продукции, степень экологичности продукции, уровень переработки отходов, а также экономический эффект от внедрения концепции устойчивой логистики на предприятии, что позволит формировать более сбалансированные программы повышения экологичности и эффективности функционирования логистических систем. 


\section{Библиографический список}

1. Дмитриев А.В. Цифровая логистика в условиях устойчивого развития // Вестник факультета управления СПбГЭУ. 2018. № 3. С.302-308.

2. Капустина Л.М. «Зеленые» технологии в логистической деятельности // Известия Уральского государственного экономического университета. 2016. № 2 (64). С.114-122.

3. Конников E.А., Конникова О.А. Тенденции устойчивого маркетинга в производстве и сбыте продукции // Вестник факультета управления СПбГЭУ. 2018. № 3. С.410-416.

4. Омельченко И.Н., Александров А.А., Бром А.Е., Белова О.В. Основные направления развития логистики XXI века: ресурсосбережение, энергетика и экология // Гуманитарный вестник МГТУ им. Н.Э. Баумана: электрон. журн. 2013. № 10 (12). URL: http://hmbul.bmstu.ru/catalog/econom/log/118.html.

5. Рыкалин А. Логистическое обеспечение и сопровождение реализации экологических ресурсосберегающих проектов // Логистика. 2015. № 11. С. 46-50.

6. Сакал П., Фидлерова Х. Стратегия устойчивой логистики как часть бизнес-стратегии // Проблемы развития территории. 2013. № 3 (65). С. 25-30.

7. Соколова Е.Л. Корпоративная социальная ответственность в управлении логистической деятельностью организации // Логистические системы в глобальной экономике. 2018. № 8. С. 235-237.

8. Юлдашева О.У., Соловьева Ю.Н., Погребова О.А., Халина Е.В., Ширшова О.И. Устойчивый маркетинг: теория и практика устойчивого потребления: монография. Санкт-Петербург. 2017.

9. Gromov V. Green Logistics in Russia (Review article) // Russian Journal of Logistics and Transport Management. 2014. Vol. 1. No. 2. P. 36-44. 